\title{
Responsibility in dealing with genetic risk information
}

\author{
Sabine Wöhlke ${ }^{1} \cdot J^{\text {Jlia Perry }}{ }^{1}$
}

Published online: 20 December 2019

(c) The Author(s) 2019

\begin{abstract}
Predictive testing information raises questions about risk communication, health responsibility, and about how to deal with the gap between knowledge of risks and options to act on this knowledge. For some diseases identified by predictive testing, specific treatments or interventions are available, while other diseases, thus far, remain untreatable or unpreventable; this triggers different forms of responsibility. Gender also often intersects with moral responsibility, regarding risk communication but also responsibilities of care which may become necessary with a family member's onset of disease. The aim of the study was to analyze laypeople's attitudes towards predictive testing with a special focus on forms of responsibility arising while dealing with uncertainty of risk information. We conducted seven focus groups with laypeople $(n=43)$ in four German cities in 2016. Participants were provided with different genetic testing scenarios (breast cancer, early-onset Alzheimer's disease, pharmacogenetics in rectal cancer) for discussing their responsibilities and risk perceptions. We identified three different forms of responsibility: self-responsibility and self-care, family responsibility and care for others, and professional responsibility. For laypeople, the decision for predictive genetic testing seems voluntary and free from external constraint; however, both family and professional conditions influence an individual's decision.
\end{abstract}

Keywords Responsibility · Predictive genetic testing $\cdot$ Laypeople's attitudes · Focus group discussion $\cdot$ Risk information

Submission for the Special Issue: 'ESHMS Conference ST\&H Special Issue.'

Electronic supplementary material The online version of this article (https://doi.org/10.1057/s4128 5-019-00127-8) contains supplementary material, which is available to authorized users.

Sabine Wöhlke

sabine.woehlke@medizin.uni-goettingen.de

Julia Perry

julia.perry@medizin.uni-goettingen.de

1 Department of Medical Ethics and History of Medicine, University Medical Center Göttingen, Humboldtallee 36, 37073 Göttingen, Germany 


\section{Abbreviations}

AD Alzheimer's disease

BC Breast cancer

RC Rectal cancer

FG Focus group

\section{Background}

New technologies of predictive testing enable the early detection of diseases prior to their onset (Marzuillo 2014; Evans et al. 2001). The aim of predictive testing is to reduce morbidity and mortality with targeted screening, diagnostic classification, surveillance, and prevention when possible (Etchegary and Fowler 2008; Evans et al. 2001). Results of predictive testing can support the tested individual in making informed decisions about medical care, future life, and family planning, help avoid unnecessary clinical investigations, and potentially expedite research (Marzuillo 2014; Burke et al. 2011).

Predictive testing may entail identifying a person's risk of developing a disease. The term "risk" as such refers to potential negative outcomes or events, instead of uncertainty, which means that the outcomes of a decision or a future event are not known (Han et al. 2013). Some studies point out that laypeople evaluate genetic risk information and understand genetic risk in a different manner (Wöhlke et al. 2019). The perception of laypeople seems to be influenced by their own circumstances, their experience with diseases, their attitudes and convictions, as well as their psychosocial well-being (Rauscher et al. 2018; Archibald and McClaren 2013). Thus, laypeople often try to reinterpret risk information in a qualitative everyday manner and ultimately rely on their intuition as a quantitative concept when deciding on predictive test results (e.g., Gigerenzer and Gray 2011; Wöhlke et al. 2019). For many medical laypeople, risk therefore remains a vague uncertainty.

While the aims of predictive testing sound promising and owning risk information can be regarded as empowering, uncertainty and potential psychosocial burden raise ethical concerns regarding the desirability and value of such risk information (Marzuillo 2014). Knowledge of probabilistic information generates obligations to act in the present concerning the potential, unclear future (Rose 2007). However, such obligations depend on the specific condition and predicted harm associated with it (Etchegary and Fowler 2008; d'Agincourt-Canning 2001). In this context, heredity and treatability play an important role in the potential value or harm of predictive information (Falahee et al. 2018). Receiving risk information cannot only cause psychological harm but also stigmatization and can lead to discrimination (Ross et al. 2013; Featherstone et al. 2006). Decisional autonomy in the context of risk information must be considered especially for vulnerable or marginalized groups such as children or cognitively impaired people but also for people who may not even have access to such services (Berkman and Hull 2014). The legitimacy of disclosing or not disclosing risk information is dependent on the quality of the informed consent procedure which may require higher standards for vulnerable and marginalized groups (Hallowell et al. 2003; 
Watson et al. 1999). Moreover, whether predictive knowledge will actually entail an increase in choices and initiate responsible behavior remains unclear (Schick$\operatorname{tanz} 2018$ ). Schicktanz (2018) highlights that responsibility is an important term to describe, understand, and formulate moral assumptions related to the individual and the social handling of risks. The responsible agency is descriptively utilized to describe the moral language of laypeople when addressing, for example, family responsibility in the case of disclosing of genetic risk information (Leefmann et al. 2017). Schicktanz (2018) differentiates between different forms of genetic responsibility: self-responsibility, family responsibility, and responsibility of healthcare professionals. This poses the theoretical anchor point of this empirical analysis.

Predictive knowledge bears not only epistemic uncertainty but also obligations for managing life although knowledge of risk information does not necessarily entail the means to alter the future (Rose 2007). Taking responsibility for one's own health may not be new, but in the era of predictive testing, such layers of responsibility may shift from a right to know to a duty to know (Domaradzki 2015; Etchegary and Fowler 2008). In clinical practice, it has been observed that individuals who undergo genetic testing often perceive their freedom to choose between different options to be constrained, e.g., by family or personal circumstances (Hallowell 1999). Thus, being informed about one's individual genetic condition can raise conflicting views regarding the right not to know, individuals often are put in the position of balancing autonomy and responsibility (Chopra and Kelly 2017; Lemke 2004; Hallowell et al. 2003). Both the right not to know and the right to know imply an uptake of responsibility for the resulting consequences. Empirical studies have shown that genetic risk information often generates unanticipated ethical dilemmas suggesting a lack of awareness of familial implications such information may have (Berkman and Hull 2014; Hallowell et al. 2003). Most ethical issues occurring in genetics relate to tension between the wishes or interests of different individuals involved (Clarke and Wallgren-Pettersson 2019).

In the wake of advancing medical technologies and increased societal interest in gaining genetic information, also in non-high risk families, family constructions as well as relationships play a significant role. For example, testing children or other family members can breach the confidentiality and the privacy of genetic information and ignore the specific moral status of a person (Rose 2007; Featherstone et al. 2006). In the context of predictive testing, gender also often intersects with moral responsibility, not only regarding risk communication but also regarding responsibilities of care which may become necessary with a family member's onset of disease (Etchegary and Fowler 2008).

Moreover, perception of disease risks is highly individual and can be challenging and distressing due to its lack of definition. Thus, framing one's own disease biography should remain an individual decision, especially as severe disease can cause biographical disruptions (Lupton 2012). However, while individuals seeking predictive testing may be framed as self-determined and able to consider values and harms of such test results, responsibilities driven by moral obligations may impact an individual's decisions (Rose 2007). Etchegary and Fowler (2008) have shown that genetic risk, independent of the results, will induce feelings of responsibility. 
The deliberations above highlight that predictive testing triggers varying conceptions of responsibility, which are strongly affected by social meanings, constructions, and practices. This has an effect on who becomes responsible, who feels responsible, and also on expectations relatives may have towards someone else being tested, hence opening new forms of genetic responsibility (Leefmann et al. 2017; Etchegary and Fowler 2008; d'Agincourt-Canning 2001). The implications of predictive technologies affect not only individuals but also professionals. In the context of risk profiling and risk perception, professionals' responsibilities concern explaining not only what genetic information means but also which potential consequences it may have for the individual and other affected people. This not only necessitates educational training of those conducting the counseling but also requires an assessment of when, how, and to whom such information should be communicated if family members may be at risk (Francis 2014; Lemke 2004; Hallowell et al. 2003; Watson et al. 1999).

Ways of dealing with genetic risk information are becoming increasingly relevant in the age of electronic healthcare records. In the course of this shift, risk information becomes more attractive for laypeople in the role of patients as well as a multitude of other actors, e.g., health insurance companies or insurance companies in the healthcare system (Wöhlke et al. under review). There are currently considerable differences in the implementation of e-health concepts, the available infrastructure, the actual use of these opportunities, and appropriate measures to strengthen all actors in the healthcare system with digital literacy in various countries (Bertelsmann Stiftung 2019).

To date, no such empirical studies exist focusing on underlying responsibilities in reflections about predictive risk information and little is known about how such responsibilities are triggered or which moral convictions they are based on (Parsons and Atkinson 1992). With this analysis, we aim to scrutinize the following questions:

What role do responsibilities play for medical laypeople in dealing with predictive testing and test results?

How are laypeople's responsibility and expectations shaped in the context of predictive testing?

How can different forms of responsibility be identified that, in turn, become relevant for (personal and) clinical communication?

Assessing laypeople's perceptions and expectations towards predictive testing becomes especially appealing in the context of Germany: a country with an advanced genetic research sector and highly developed diagnostic facilities, however, with a restrictive system. According to the German Genetic Diagnostics Act (GenDG), a counseling session with a trained and specialized counselor/physician is obligatory before a predictive test for medical purposes can be carried out.

Our data originate from an interdisciplinary study which focuses on how laypeople or family members take a stance towards predictive tests or towards gaining knowledge about such predictive information. 


\section{Methods}

We conducted seven focus groups with laypeople $(n=43)$ in four German cities (Göttingen, Berlin, Frankfurt (Main), and Cologne) in late 2016 with a varied sample. In order to reach a large group of laypeople, we pursued a mixed recruitment strategy. We recruited participants through flyers and posters sent to public institutions (libraries, cultural centers, vocational schools, technical colleges) in the abovementioned cities. On the other hand, online social media (e.g., Facebook), mailing lists (e.g., sports or nutrition groups), and small online ads (e.g., digital and print and postings on virtual bulletin boards) were used. Participants who were interested in our study were asked to provide sociodemographic information (age, gender, educational level, profession, religion, marital status, number of children, and previous experience with genetic testing). On the basis of this sociodemographic data, we had a large pool of interested participants for putting together socially varied groups.

All participants were invited by e-mail and received an information sheet which superficially describes the general topics to be dealt with in the topics of the focus group. This approach was useful as the guide was quite comprehensive and left no room for content questions. We used a structured discussion guideline (Suppl. 1) and case vignettes as discussion starters for the participants (Barbour 2007). ${ }^{1}$ All discussions were audio-recorded and later transcribed and pseudonymized for conducting a content analysis (Metschke and Wellbrock 2002). Each group was moderated by two researchers.

The focus group (FG) guideline consisted of three realistic disease scenarios, including predictive genetic testing for breasts cancer (BC), early-onset Alzheimer's disease (AD), and pharmacological genetic testing in rectal cancer (RC) therapy. The selection of the thematic scenarios was based on preliminary theoretical considerations. The BC scenario was chosen as the disease is associated with strong feelings of responsibility and obligations, especially in mother-daughter dyads. Further, $\mathrm{BC}$ is, in most cases, treatable and associated with high levels of risk management by means of surveillance and prevention strategies (Hallowell 1999; d'AgincourtCanning 2001). The $\mathrm{AD}^{2}$ scenario was chosen due to the ethical and social issues the disease poses and lack of efficient treatment options. On an individual and societal level, the disease is associated with fears concerning identity loss and future projections of responsibility for care (Milne et al. 2018; Karlawish 2011). The pharmacogenetics scenario in the context of RC comprising research for stratification was chosen on the basis of considering options of or reactions to non-treatment if neoadjuvant treatment is deemed to be ineffective for tumor shrinkage. Stratification here entails that neoadjuvant treatment is not given as one's body does not respond to treatment which has implications for one's health responsibility (Schneider and Langner 2014). Each case vignette was supported by slides, on which the

\footnotetext{
1 For a detailed methodological description, see Schaper et al. (2018).

2 The scenarios for the FGs were developed in 2015 and were meant to be comprehensible for laypeople. The term dementia, however, would have been more suitable in this context, as Alzheimer's disease only makes up one form of dementia.
} 
risk information was visualized (Schwartz and Woloshin 2011) (Suppl. 2). Thus, the participants received the numerical risk information both verbally and visually.

All participants were 18 years old or older, and group size varied between 3 and 9 participants (Table 1). ${ }^{3}$ Informed consent of all participants was given to us in written form after providing them with information on the study. Participants were advised that they could withdraw their participation at any time without giving reasons. Each participant received an expense allowance of $25 €$. The study was approved by the local ethics committee (IRB) of the University Medical Center Göttingen, amendment no. 16/10/14.

A qualitative content analysis was carried out (Bengtsson 2016). For the coding and analysis of the material, we used the software Atlas.ti ${ }^{\mathrm{TM}}$. We focused on comparisons of statements in each group and of individual statements as well as on the course and topics of the discussions. The aim was to identify differences in attitudes towards responsibility in genetic testing. Our coding process was based on inductive coding with three base codes (see Table 2). ${ }^{4}$ These codes were derived based on Schicktanz (2018). Second, these inductive codes were selected with regard to who plays a role as an addressee for responsibility.

\section{Different forms of responsibility towards predictive genetic testing}

Our findings overall show a welcoming attitude among most participants towards predictive testing. The FG discussion indicates that participants mainly argue on a subjective and individual level. We identified three different forms of responsibility: self-responsibility and self-care, family responsibility and care for others, and professional responsibility.

\section{Self-responsibility and self-care}

Laypeople agreed that predictive genetic testing provides information, which potentially has a strong impact on their own lives. Even though this information predicts an uncertain and probabilistic future, it is accompanied by commitments or obligations in the present that affect one's self, one's body, and one's health. Therefore, the autonomous decision should be respected if someone does not want to have a test carried out.

Mr. U: Yes, I also think that's a completely individual decision. I mean, I don't think, that there are any, like, general standards. I mean, of course, if someone from my immediate family and personal circle received such a diagnosis now, I would want the person to tell me, but that's of course the decision

\footnotetext{
3 Personal experience means the person has undergone genetic testing in the past or witnessed it in a relative or another person. Experience with prenatal diagnostics was not considered personal experience with genetic testing.

4 The presentation of participants' positions follows the scheme: many $\geq 50 \%$, some $=10-50 \%$, few $=0-10 \%$ of participants.
} 


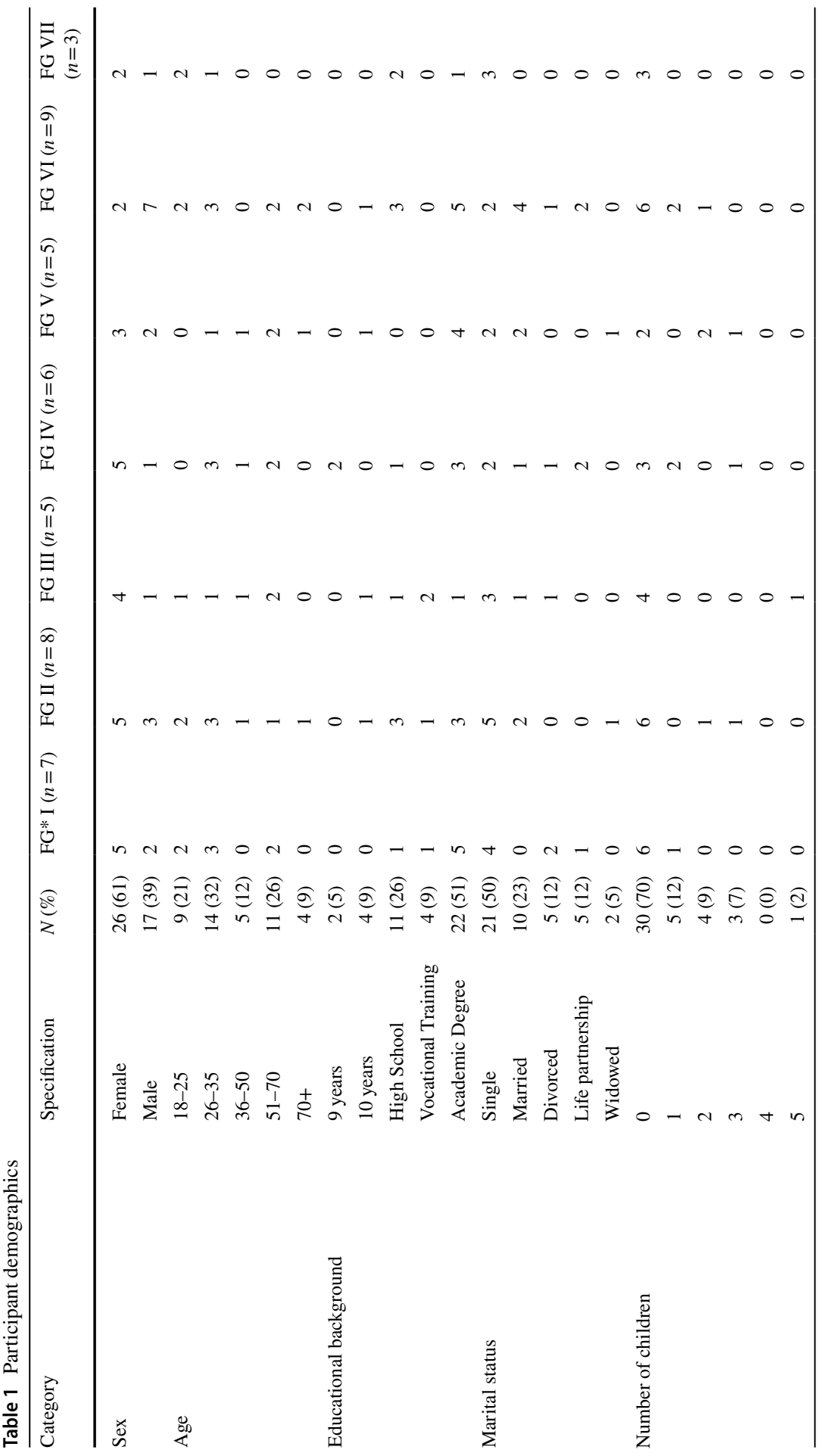




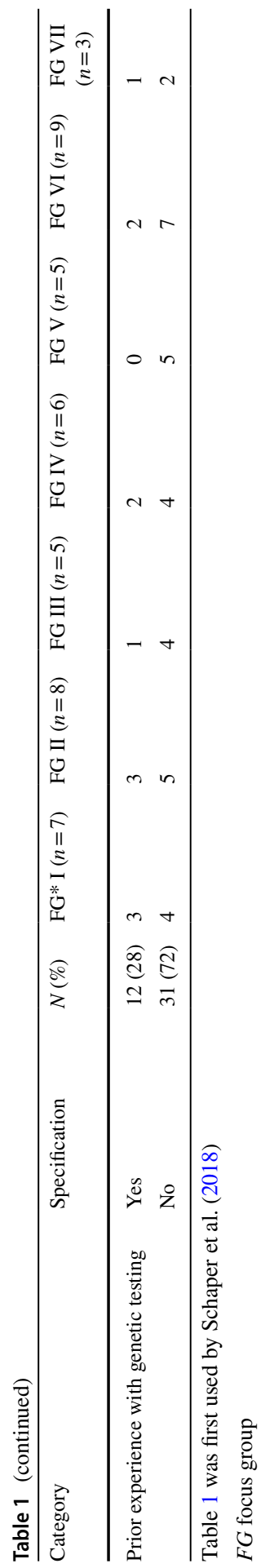

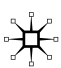




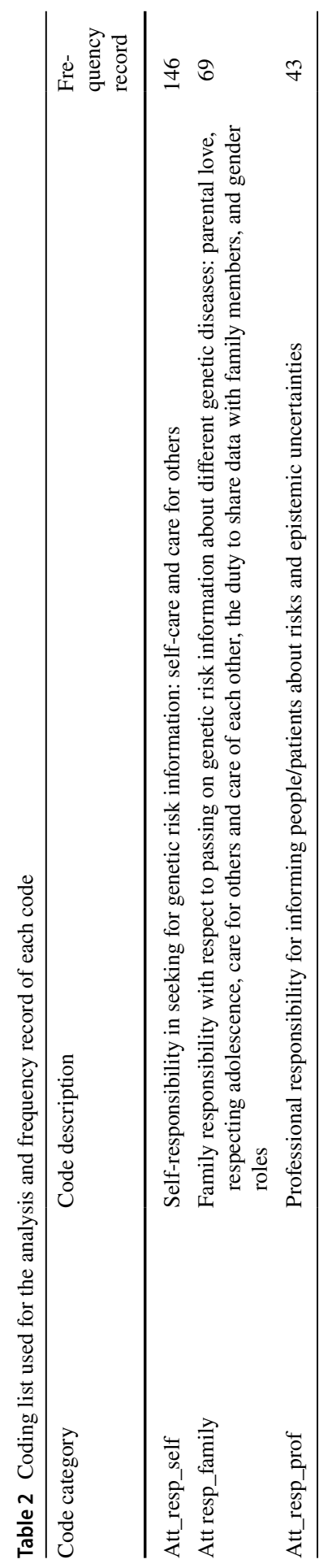


of every individual [...]. (Single, 18-25 years old, no children, no experience with genetic testing).

In addition, laypeople claimed that a test would be sensible if it produced a clear result, from which a clear course of action could emerge. The participants justified their reasoning with everyday experiences and admitted to uncertainty, as they lacked expertise in dealing with probabilistic information.

Laypeople expressed concerns about psychological burden caused by the knowledge of an increased risk for a specific disease and how this could be managed. Unease due to genetic probabilities was especially triggered by the probability value of a predictive test and by having to relate this probability to one's own life span:

Ms. H.: [...] I'm just wondering, in the case that it's confirmed that there's an elevated risk of breast cancer before the age of seventy, doesn't that put you under even more pressure? Because that's a long time span. And, like I said, there's still the risk that it won't be detected, and I wonder whether my whole life would then, for me, personally, revolve around me waiting for it to come. [...] (Single, 26-35 years old, no children, no experience with genetic testing).

In general, many participants stressed that an individual should reflect the consequences of a genetic test result against the backdrop of one's life stage before a test is carried out.

Most participants expressed uncertainty over the predictive power of genetic testing. This is often based on positive representations, from which they derive a meaningful use of this medical information. Utilization appeals to responsibility for one's own health. The knowledge of preventive measures is complicated by indeterminable factors such as time, meaning that an individual just does not know when exactly the disease will occur.

Genetic testing and new forms of prevention are integrated into the area of ordinary life, subject to measurement, attention, and medical interpretation (Hofmann and Svenaeus 2018). Therefore, participants were certain that the probabilistic genetic information would have an impact on their biography. Insecurity thus arises when laypeople have no conception of a "potential" health biography. Here, they referred to the argument of the right not to know.

The participants agreed that a pharmacological genetic test (biomarker) always makes sense, as experts could use the biomarker result (as a probability value) to better address the patients' self-determination and responsibility and actively support their health. The option of seeking a second opinion was not addressed, but rather, it was stressed that the genetic knowledge should be used to motivate people to undergo cancer treatment. ${ }^{5}$

Measures of advance care planning were mostly discussed in light of an obligation towards self-determination over one's own body and one's future healthcare:

\footnotetext{
5 This demonstrates a misconception of pharmacological tests (biomarkers), which aim at stratifying patients regarding therapeutic measures. For an in-depth analysis of this topic, see Perry et al. (2016).
}

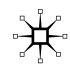


Ms. V.: I mean, perhaps also with regard to an advance health care directive or so. I mean that you might still be able to decide for yourself whether you perhaps want to move to a care home later or want to receive outpatient treatment. If you're no longer able to decide on your own at a later point that you could still make the decision before. [...] (Single, 18-25 years old, no children, previous experience with genetic testing).

Therefore, gaining results of predictive testing was regarded as an opportunity to take on individual responsibility for one's own health. Many participants, however, thought that without having specific indications, it would be difficult for them to act preventively or be proactive. An important topic was the perception of disease severity and the manner in which one can psychologically deal with a disease. Therefore, a predictive test was considered useful when the individual had the opportunity to proactively prevent the disease or impede its progression and, thus, use the "gained" time. Without treatment options, predictive testing was mostly rejected. This is justified with the concern about how and whether an individual can handle information without a possible course of action.

Thus, the participants' commitment to their own bodies was negotiated against the backdrop of the severity or image of a disease (e.g., $\mathrm{BC}=$ treatment options; $\mathrm{AD}=$ no treatment and loss of identity). This illustrates that $\mathrm{BC}$ or cancer in general is perceived as a disease that can be detected early on if people have a cautious understanding of their body and can be treated with an elaborate therapy (including surgery):

Mr. W.: [It] is a personal decision, [...]. I have a friend in the US, her mother has breast cancer and she a year ago had a test, carried out. And she also had surgery done... And, yes to my mind she's my friend. I can understand her decision. It can, she can of course wait a couple of years until, now she's about twenty-five years old. And she can of course wait until forty-five. But, hey, she decided to have surgery early on. [...] (Single, 26-35 years old, no children, no experience with genetic testing).

Thus, the image of fighting is very strongly associated with cancer, whereas issues such as palliative care and dying were rarely discussed despite the invasive therapy. For example, in the pharmacological scenario, no group discussed the option of refraining from treatment due to insufficient response and thus potentially having more quality of life over the remaining lifetime.

Although considered severe, BC for the participants had a stronger localization/positioning in the form of an affected body part. Thus, a reductionist view was constructed, i.e., the possibility of metastases or cancer being a chronic disease was not considered. In the FGs, it was further discussed that BC is a women's issue directly related to a woman's physicality; men justified their reluctance in the discussion with this assumption. The AD scenario was indirectly discussed as a women's issue in the context of care, as home-based care was often considered a women's domain. Interestingly, in the discussions, women more often addressed advance care planning than men did. 
Remarkably, responsibility was perceived entirely differently in the example of predictive testing for the early detection of early-onset AD. For participants living a very active life, the possible risk of $A D$ posed a threat they wanted to avoid. These participants drew on an image of AD that only occurs in advanced age. Younger people also felt less affected by $\mathrm{AD}$ in their present state due to its image as an old person's disease. $\mathrm{AD}$, in contrast to $\mathrm{BC}$, was regarded as rather holistic; it was seen to affect the entirety of a person which strongly affects the family/relatives/potential caregivers and exceeds own coping capabilities.

It was difficult for laypeople to maintain an individual ethical approach of reasoning towards predictive genetic information within the framework of responsibility. Schicktanz argues that self-determination "is often understood as having the freedom 'to know' or 'not to know', no third person has the right to judge or guide individual decisions regarding knowledge gathering and following actions. But these assumptions rely only on epistemic content of genetic tests." (2018, p. 17). As our results show, there is an ethical difference between the right to self-determination and the duty to know. Laypeople share both the right to autonomous decisions for predictive genetic testing and the right not to know. However, self-responsibility is not a rigid concept everyone should follow. Rather, it is a diverse, individual concept that changes or adapts over time. Thus, an individual is often portrayed as the guardian of her genetic information, who has control over its distribution and thus also can exercise power over relatives. The laypeople in our FGs, however, rather expressed the power information had over them, making them vulnerable, e.g., participants often mentioned the risk of psychological burden. An individual's genetic knowledge thus has high social relevance for other people. Moral conflict can be more pronounced when it comes to responsibility within and for the family, and to people who, e.g., are unwilling to undergo predictive testing (Featherstone et al. 2006).

Interestingly, possible discriminatory effects of genetic risk data if used by third parties, e.g., by insurance companies or an employer, were not discussed as a possible issue in the focus groups. Genetic risk data of predictive genetic tests was rather discussed and reflected in the context of possible treatment regimens.

\section{Family responsibility and care for others}

It is interesting to note that treatable diseases were considered from an individual perspective, while non-treatable diseases were rather considered on a collective level involving family, caretakers, or society. The benefits of predictive genetic information created high hopes for helping the family or the next generation. It is thus possible to appeal to responsibility towards one's own children to be tested at an early stage in order to act preventively.

The participants agreed that having a family presupposes responsibility for other people and certain behaviors are expected:

Ms. H.: Yes, I mean, someday, it's no longer just about yourself [...] some-

day, you'll have a family, and someday, you'll have responsibility, and you'll also be part of a family you started yourself, and I think that really is a dif- 
ferent situation then [...] (Single, 26-35 years old, no children, no experience with genetic testing).

Decisions for predictive genetic testing can be based on the wish to provide certainty to relatives and thus enable them to follow through with preventive checkups. This seems to have a psychological effect of relief for many participants. Even when participants were not confronted with genetic information, they referred to experiences made within the family. Predictive testing in this context seemed to provide certainty and serves the purpose of counteracting insecurities and fear based on discovering a disease too late:

Ms. I.: Well, in my family, my grandmother, she had breast cancer too, she had her breast removed. And my mother said to me, this one time, you need to know that we're living with the risk, you know what you can do about it and the rest is your decision. And personally, I find that very comfortable. You know it runs in our family, see to it. And decide for yourself and I thought that was the best way to do it. (Single, 18-25 years old, no children, no experience with genetic testing).

Further, the life course and age were dominant in perceptions of life and/or family planning. It was relevant to participants where an individual stands in life. The underlying theme was whether relevant goals in life had been achieved and in which responsible position, an individual is situated. Accordingly, many participants considered it a burden to be informed about a high disease risk at a young age (i.e., $<30$ years), which infringes on life to come and could cause psychological distress.

Predictive genetic information may alter a family's biography. Participants expressed skepticism about predictive information due to their lack of experience in dealing with such changes. Thus, AD could also have serious consequences for the distribution of roles or role expectations within families and could undermine individuals' self-determination in families.

Mrs. X.: In the past, no one cared about it. That's just the way it was. People lived with their family, elderly people. They sometimes were a little scatter-brained, so what (laughs), that wasn't so bad, right? You just managed together. And today, everything's already so perfectly classified, everything. I don't know whether that's so good. Maybe you worry too much as a consequence. I think if it's severe forms that significantly change the behaviour, right? That's sometimes the case, especially when it comes to Alzheimer's disease. That changes the behaviour so fundamentally, then it's of course advisable to help the persons professionally, right? (Single, 51-70, no children, no experience in genetic testing).

For many participants, their perceived family responsibility led to a family obligation to share genetic information with relatives.

Ms. H.: Well, I think, if you have a genetic disease that is inheritable, you're obliged in a way to inform your family. [...] I think if you become aware 
that you have a hereditary disease, you are obliged to tell the other family members that the disease runs in the family. (Single, 26-35 years old, no children, no experience with genetic testing).

This quote illustrates that although a family obligation is formulated, it does not take precedence over the interests of the individual. This also means, however, that family members have the right to know in the case of a hereditary genetic disease. It was considered an enormous burden not to share this important information with other family members.

Mrs. P.: Okay, I'd tell my daughter, among others, for example, because she really should get herself tested too. Because it's really in our... I just counted, there were at least five cases of death, really within my blood-related family. But well, you can't generally, you have to decide for yourself ... whether you, whom you'll tell. (Widowed, 70+ years old, three children, no experience with genetic testing).

However, some participants recognized that a good, intimate relationship is a prerequisite for sharing such information, as the information should be discussed and solutions should be sought jointly. Especially younger participants saw the benefit of gaining early knowledge about someone possibly developing AD within the family, so that the family could consider advance care planning and could also make financial provisions for care. Considering responsibility for the family, the consequence of not knowing can entail substantial financial burden, e.g., for care of a family member.

Ms. H.: Well, in that case for example, I would take out a long-term care insurance before I get the diagnosis. Because the question is, at which rate you still get one then. [...] especially at an old age, in cases of people who are in need of long-term care, the financial factor is, it can, it can bring about a family's ruin. (Single, 26-35 years old, no children, no experience with genetic testing).

For other participants, however, a high disease probability posed such a burden that they found it difficult to imagine sharing this information with their relatives and placing this burden on them:

Ms. I.: Well, I don't think I'd do it because I also think it's enough, I mean, in case of doubt, it's already enough to burden myself with it. So, I think I simply wouldn't want the people who are close to me to worry a lot about it in any way. I mean, no. (Single, 18-25 years old, no children, no experience with genetic testing).

It becomes clear that laypeople had an ambivalent attitude in passing on genetic information: On the one hand, they saw a moral conflict in the dissemination of information to family members due to the imposed burden. On the other hand, many participants saw a moral obligation to pass on genetic information. Most family relationships are characterized by role expectations and norms that restrict individuals in their lives and decisional sovereignty. It does not matter whether these are pre-defined relationships (as between siblings) or freely chosen relationships (as 
between spouses). People are expected to show a high level of patience, cooperativeness, generosity, and tolerance towards their loved ones-often more than would be required by friends (Featherstone et al. 2006).

In this context, a gender-specific pattern became apparent, especially in early BC detection, where sharing genetic information with daughters if often expressed as a moral duty (Baars et al. 2016). BC is associated with the female body and declared as a so-called women's issue, so that men here withdraw from their responsibility (Sorenson et al. 2004). While there were no gender differences regarding the acceptance of an $\mathrm{AD}$ test, due to lack of therapeutic options, the benefits of advance care planning were more frequently addressed by women. Here, conclusions can be drawn towards a gendered model of care. It becomes clear that different familial responsibilities emerge in the context of predictive genetic information (Featherstone et al. 2006). For example, gender-specific role expectations exist within families, which have relevance for the social structure of responsibilization.

In addition, our results show that this obligation does not include a collective decision-making framework (Beier et al. 2016). Rather, the obligation is based on an assumption that a female family member has made an individual decision to have predictive genetic testing carried out without first consulting the family about how they want to deal with this genetic information. The latter includes a deliberative approach, in which all people in a group can make self-determined decisions, without having obligations to pass on information. This would entail that questions about the right to know or even the right not to know are addressed in a deliberative manner as collective actors. Moreover, our data showed that the concept of family and feelings of responsibility shift when an individual starts her own family. The desire for social support from relatives, instead of feelings of obligation, may increase as a young adult begins a life with a significant other (Greenberg and Smith 2015; Whyte et al. 2016).

\section{Professional responsibility}

For predictive genetic testing, participants agreed that professionals have a special responsibility because only they can competently interpret genetic information. The professionals' responsibility above all is to communicate genetic information to the patient in a comprehensible manner, so that the information and potentially resulting consequences can be understood and queries can be addressed. Participants expressed clear expectations towards professionals:

Ms C.: Yes, also make the decision together, what I might want to do. You also want to get it off your chest yourself, I mean, talking to a doctor is also often somehow. And also talk about it openly with my partner, but really come along to the doctor too, to the psychologist, maybe also support in some way, not pushing it, of course, but so that you, he also knows, if there's a problem, he can also go somewhere and can talk to someone else, not only to me, but also to someone else perhaps, a doctor or so. (Partnership, 36-50, one child, no experience with genetic testing). 
With such complex information, many participants stated that they would prefer a paternalistic physician-patient relationship because they knew they could not interpret the information without medical expertise:

Mr. T.: So, you would. You would rely on this judgement by a doctor you trust, who says, okay, there are certain viewpoints, and according to my experience, I'd have it removed, period. (Married, 51-70, two children, no experience with genetic testing).

Physicians/geneticists should also feel responsible for the fact that genetic information has far-reaching and grave consequences for individuals as well as their families. This requires qualified psychological staff as part of the counseling session. For laypeople, predictive genetic information regarding AD and the option of considering advance care planning only makes sense if a family can fall back on support services or financial support from the state, e.g., regarding care. If the individuals or families were not to receive sufficient support from professionals, they rejected the test due to excessive burden. The genetic test results in the form of numbers, however, only made sense in combination with a physician-patient relationship.

Some participants had a stricter approach to predictive testing. In their opinion, only genetic testing should be performed. This entails that physicians should only prompt predictive testing in a suspected case where heredity is relevant. Without specific reasons and the prospect of treatment, predictive genetic testing should not be performed. Criticism is hereby also indirectly aimed at people without a medical indication or family history who want to have predictive testing carried out. In this view, physicians are granted the sole right to order a test.

In addition, participants questioned who determines the norms and limits of probabilities in medicine/genetics. It was also queried, who decides where the line is and who decides when a finding must be communicated or not? With this, it was criticized that medical laypeople and, in some circumstances, also patients are insufficiently involved in such decision-making processes, and experts rely only on numbers and algorithms without including the actually affected.

Mrs. N.: Who determines the norm? Who says, depending on what you find and see what's, what's conspicuous, what's unhealthy, what's pathological, what does it mean, do you have to say. Who, who, who determines that? From which point onwards there would be an information obligation, or not. After all, medicine is getting more and more accurate, is getting more and more, is able to detect more and more, so, who decides in case of doubt? (Married, 36-50 years old, two children, previous experience with genetic testing).

Participants expressed a need for professional guidance that goes far beyond the approach of genetic counseling. Above all, the moral dimensions such as the "right to knowledge," "autonomy," "choice," and "responsibility" became relevant, which in turn are dependent on professionals' responsibility. From a layperson's perspective, professional responsibility implied a physician-patient 
relationship that should include interpersonal levels and therefore should be based on a partnership. They emphasized that trust is required for a successful physician-patient relationship (Wouters et al. 2016). Therefore, it is not surprising that laypeople did not regard medical staff as people who would make use of predictive data and would abuse data protection (Schaper et al. 2018). However, the current practice of predictive genetic testing seems to negatively affect professional responsibility. For professionals, ethical issues can arise that may lead to tensions between the professional obligation to respect a patient's autonomy and privacy, while preventing potential harm of family members (Arribas-Ayllon et al. 2011). Ethical principles such as autonomy, confidentiality, or non-directivity are touched upon in this context. It seems to be problematic for medical practitioners to assess when it is appropriate to warn relatives about hereditary risks (Gilbar et al. 2016). Recently, there have been cases in which physicians were sued for withholding such information. ${ }^{6}$ Other studies show that physicians have shared genetic information with relatives without a person's consent (Clarke et al. 2005). Therefore, an ethics of care provides a constructive outlook on these issues. Weaver (2016) argues that an ethics of care supports the physician to foster her relationship with the patient and to respect the patients' considerations on what is good for her own relatives, instead of putting the relationship at risk by breaching confidentiality and consent. Care ethics can be interpreted as a plea for responsiveness of patients towards a family's needs (Wouters et al. 2016). Wouters et al. (2016) conclude that family depicts a relationship that care ethics describes as central to moral obligations of individuals.

\section{Limitations}

Some limitations pertain to this research. This work is exploratory in nature and subject to a number of limitations in terms of representativeness. In view of the narrow research area and the research questions, the overall target group is very small. We cannot generalize our results to the broader population, but we can assume that they are somewhat representative for the overall small target group.

In addition, our sample provides some homogeneity. Despite a long recruitment phase, we might have had an impact: more women than men took part in the focus groups and people between 30 and 50 were underrepresented (the typical age of people working day jobs and are thus less likely to sacrifice free time for study participation).

Besides, it is difficult to account for how individual personality traits may influence responses to genetic testing. How people deal with genetic information may depend on many different factors; this is not unique to information gained from genetic testing per se. We wanted to show with our analysis how different argumentations of responsibility influence how people deal with genetic information.

\footnotetext{
${ }^{6}$ https://www.theguardian.com/science/2018/nov/25/woman-inherited-fatal-illness-sue-doctors-groun dbreaking-case-huntingtons [15.12.2018].
} 


\section{Concluding remarks}

Our empirical results show that German laypeople address different forms of responsibility in the context of predictive testing. Overall, the three forms of responsibility emerging from the laypeople's arguments are characterized by their lived everyday morality. This is linked to the legal framework and reflects the assumption that family relationships are associated with particular obligations.

Predictive testing can be regarded as a form of medical technology, which affects the way people think about and perceive their health status (Lupton 2012). Accordingly, genetic information is also a constituent part of a person; thus, it is not surprising that self-responsibility is predominantly referred to in the context of self-care. Lay concepts of responsibility in the context of predictive testing involve moral questions about respecting self-determination, discreetness, control, and prevention (Konrad 2005). For laypeople, the consequences of predictive testing are relevant, and while they may vary on an individual basis, they always entail far-reaching responsibilities (Daly et al. 2016; Domaradzki 2015; Etchegary and Fowler 2008). Although the decision for predictive testing seems voluntary and without external constraint, both family and professional conditions influence an individual's autonomous decision. It becomes clear that the forms of responsibility identified often overlap and mutually condition each other. Individual responsibility is strongly influenced by family responsibility which, in turn, has a major impact on professional responsibility and relates to relational autonomy (Mackenzie and Stoljar 2000). Professional responsibility, on the one hand, becomes necessary for patient-centered physician-patient relationships and, on the hand, for psychological support which becomes necessary for individuals and families regardless of the result of their predictive test (Timman et al. 2004). Individuals may need assistance not only in understanding the risk information but also in assessing who else may be affected by this information (Hallowell et al. 2003; Watson et al. 1999).

In the case of predictive diseases, for which no effective treatment approaches exist to date, the concern predominates about uncontrollable disadvantages up to the fear of a "genetic lower class" (Lemke 2016; Keays 2000), in that people are disadvantaged, pathologized, and stigmatized because of their genetic characteristics. Our results regarding biographical changes through predictive genetic information also point to future, unforeseeable fears of new forms of social categorization and negative classification based on genetic risk information. This legitimate concern becomes particularly relevant in the case of the "right to know" and a "duty to know." Within the framework of the individual's responsibility, the tendency, due to insecurity described above, is to place the individual's decision above obligations to the family. Strict state regulations are urgently needed to help people with predictive genetic risk information, which can also have far-reaching consequences for the family, to make their decisions regarding sharing of their risk information by protecting them from discrimination.

The increasing availability of genetic information, however, does create a sense of commitment to family members to share this information (Gilbar et al. 2016; Whyte et al. 2016). It becomes evident that relational autonomy is formulated beyond close 
social bonds and shifts towards professionals when relevant for the decision. Our findings illustrate how responsibility, as a key term in moral deliberations, is embedded in lived experience and how relational understandings of an individual's duties und rights are embedded in social contexts. Raz and Schicktanz (2009) have pointed out that some of these deliberations are related to different individual understandings of responsibility, predictability, and trust concerning genetic testing which also differ culturally. Although our findings cannot be generalized, they can support genetic health professionals in adapting to clients' or patients' needs and expectations of professional responsibility.

An individual exists within a network of relationships that is influenced by obligations and responsibilities. Therefore, genetic counseling should also help individuals reflect on the extent to which their decisions and actions are based on family responsibility and increasing self-awareness and not try to eliminate the influence of duties and obligations (Whyte et al. 2016).

The participants in our study seemed to link potential stigmatization or discrimination generated by genetic risk data rather to social and emotional aspects than to institutional power. This could be due to the relatively restrictive system in Germany regarding genetic research, which places high value on data privacy (Kalokairinou et al. 2018). Regulations, apart from the GenDG, will have to be adapted if predictive genetic testing services become more easily accessible for individuals without requiring counseling sessions with a specialist.

Numerous studies with international comparisons have shown that people are disadvantaged or excluded by health insurance companies, employers, and authorities due to genetic traits (Lemke 2016). Such findings surprisingly do not coincide with our study. This is noteworthy as the reduction of potential discrimination strongly touches upon professional responsibility. The fact that participants in our study were not concerned about possible termination of their health insurance can be seen as an indication that the participants, on the one hand, argue against the backdrop of a very strict Diagnostics Act in Germany, and, on the other hand, they seem to have a considerable lack of knowledge regarding risk information and its potential implications.

Acknowledgements The authors want to thank Silke Schicktanz for leading the project as well as Manuel Schaper and Zümrüt Alpinar-Sencan for their excellent editing.

Author Contributions Sabine Wöhlke and Julia Perry equally contributed to the design of the work, analysis, and interpretation of data, as well as the drafting and revising of the manuscript, approved the final version to be published, and agreed to be accountable for all aspects of the work.

Funding This research was funded by the Swedish Riksbankens Jubileumsfond, 2015-2019 (Grant No. 1351730).

Open Access This article is licensed under a Creative Commons Attribution 4.0 International License, which permits use, sharing, adaptation, distribution and reproduction in any medium or format, as long as you give appropriate credit to the original author(s) and the source, provide a link to the Creative Commons licence, and indicate if changes were made. The images or other third party material in this article are included in the article's Creative Commons licence, unless indicated otherwise in a credit line to the material. If material is not included in the article's Creative Commons licence and your intended use is not permitted by statutory regulation or exceeds the permitted use, you will need to obtain permission directly from the copyright holder. To view a copy of this licence, visit http://creativecommons.org/licen ses/by/4.0/. 


\section{References}

Archibald, A.D., and B.J. McClaren. 2012. Perceived relevance of genetic carrier screening: observations of the role of health-related life experiences and stage of life in decision making. Journal of Community Genetics 3: 47-54.

Arribas-Ayllon, M., S. Sarangi, and A. Clarke. 2011. Genetic testing. Accounts of autonomy, responsibility and blame. London: Routledge.

Baars, J.E., M.G. Ausems, E. van Riel, M.C. Kars, and E.M. Bleiker. 2016. Communication between breast cancer patients who received inconclusive genetic test results and their daughters and sisters years after testing. Journal of Genetic Counseling 25 (3): 461-471.

Barbour, R.S. 2007. Doing Focus Groups. London: Sage Publications.

Beier, K., I. Jordan, C. Wiesemann, and S. Schicktanz. 2016. Understanding collective agency in bioethics. Medicine, Health Care and Philosophy 19 (3): 411-422.

Bengtsson, M. 2016. How to plan and perform a qualitative study using content analysis. NursingPlus Open 2: 8-14.

Berkman, B.E., and S.C. Hull. 2014. The 'right not to know' in the genomic era: Time to break from tradition? The American Journal of Bioethics 14 (3): 28-31.

Bertelsmann Stiftung (ed.): Thiel, R., Deimel, L., Schmidtmann, D., Piesche, K., Hüsing, T., Rennoch, J., Stroetmann, V., Stroetmann, K. (empirica). 2019. \#SmartHealthSystems, International comparison of digital strategies, https://www.bertelsmann-stiftung.de/en/publications/publication/did/smarthealt hsystems-1/.

Burke, W., et al. 2011. Genetic screening. Epidemiologic Reviews 33 (1): 148-164.

Chopra, I., and K.M. Kelly. 2017. Cancer risk information sharing: The experience of individuals receiving genetic counseling for BRCA1/2 mutations. Journal of Health Communication 22 (2): 143-152.

Clarke, A., M. Richards, L. Kerzin-Storrar, J. Halliday, M.A. Young, S.A. Simpson, K. Featherstone, K. Forrest, A. Lucassen, P.J. Morrison, O.W. Quarrell, H. Stewart, and collaborators. 2005. Genetic professionals' reports of nondisclosure of genetic risk information within families. European Journal of Human Genetics 13: 556-562.

Clarke, A.J., and C. Wallgren-Pettersson. 2019. Ethics in genetic counselling. Journal of Community Genetics 10 (1): 3-33.

D'Agincourt-Canning, L. 2001. Experiences of genetic risk: Disclosure and the gendering of responsibility. Bioethics 15 (3): 231-247.

Daly, M.B., S. Montgomery, R. Bingler, and K. Ruth. 2016. Communicating genetic test results within the family: Is it lost in translation? A survey of relatives in the randomized six-step study. Familial Cancer 15 (4): 697-706.

Domaradzki, J. 2015. Patient rights, risk, and responsibilities in the genetic era: A right to know, a right not to know, or a duty to know? Annals of Agricultural and Environmental Medicine 22 (1): $156-162$.

Etchegary, H., and K. Fowler. 2008. 'They had the right to know.' Genetic risk and perceptions of responsibility. Psychology \& Health 23 (6): 707-727.

Evans, J.P., C. Skrzynia, and W. Burke. 2001. The complexities of predictive genetic testing. BMJ (Clinical Research ed.) 322 (7293): 1052-1056.

Falahee, M., G. Simmons, K. Raza, and R. Stack. 2018. Healthcare professionals' perceptions of risk in the context of genetic testing for the prediction of chronic disease: A qualitative metasynthesis. Journal of Risk Research 21 (2): 129-166.

Featherstone, K., P. Atkinson, A. Bharadwaj, and A. Clarke. 2006. Risky relations: Family, kinship and the new genetics. New York: Berg.

Forrest, K., S.A. Simpson, B.J. Wilson, E.L. Van Teijlingen, L. McKee, N. Haites, and E. Matthews. 2003. To tell or not to tell: Barriers and facilitators in family communication about genetic risk. Clinical Genetics 64 (4): 317-326.

Francis, L.P. 2014. Genomic knowledge sharing: A review of the ethical and legal issues. Applied \& Translational Genomics 3 (4): 111-115.

Gigerenzer, G., and J.A.M. Gray. 2011. Launching the century of the patient. In Better doctors, better patients, better decisions. Envisioning Health Care 2020, ed. G. Gigerenzer and J.A.M. Gray, 3-28. Cambridge, MA: MIT Press.

Gilbar, R., S. Shalev, R. Spiegel, E. Pras, M. Berkenstadt, M. Sagi, A. Ben-Yehuda, P. Mor, S. Perry, T.F. Zaccai, Z. Borochowitz, and S. Barnoy. 2016. Patients' attitudes towards disclosure of genetic test 
results to family members: The impact of patients' sociodemographic background and counseling experience. Journal of Genetic Counseling 25 (2): 314-324.

Green, J., and N. Thorogood. 2009. Qualitative methods for health research. London: Sage.

Greenberg, M., and R.A. Smith. 2015. Support seeking or familial obligation: An investigation of motives for disclosing genetic test results. Journal of Health Communication 31 (6): 668-678.

Hallowell, N. 1999. Doing the right thing: Genetic risk and responsibility. Sociology of Health \& Illness 21 (5): 597-621.

Hallowell, N., C. Foster, R. Eeles, A. Ardern-Jones, V. Murday, and M. Watson. 2003. Balancing autonomy and responsibility: The ethics of generating and disclosing genetic information. Journal of Medical Ethics 29 (2): 74-79.

Han, P.K.J., N. Hootsmans, M. Neilson, B. Roy, T. Kungel, C. Gutheil, M. Diefenbach, and M. Hansen. 2013. The value of personalised risk information: A qualitative study of the perceptions of patients with prostate cancer. British Medical Journal Open 2013 (3): e003226. https://doi.org/10.1136/ bmjopen-2013-003226.

Hofmann, B., and F. Svenaeus. 2018. How medical technologies shape the experience of illness. Life Sciences, Society and Policy. https://doi.org/10.1186/s40504-018-0069-y.

Kalokairinou, L., H.C. Howard, S. Slokenberga, et al. 2018. Legislation of direct-to-consumer genetic testing in Europe: A fragmented regulatory landscape. Journal of Community Genetics 9 (2): $117-132$.

Karlawish, J. 2011. Addressing the ethical, policy, and social challenges of preclinical Alzheimer disease. Neurology 77 (15): 1487-1493.

Keays, D. 2000. When is genetic discrimination justified? Monash Bioethics Review 19 (4): 79-88.

Konrad, M. 2005. Narrating the new predictive genetics: Ethics, ethnography and science. Cambridge: Cambridge University Press.

Leefmann, J., M. Schaper, and S. Schicktanz. 2017. The concept of "Genetic Responsibility" and its meanings: A systematic review of qualitative medical sociology literature. Frontiers in Sociology 1: 18 .

Lemke, T. 2004. Disposition and determinism: Genetic diagnostics in risk society. Sociological Review 52 (4): 550-566.

Lemke, T. 2016. Rethinking biopolitics: The new materialism and the political economy of life. In Resisting biopolitics: Philosophical, political, and performative strategies, ed. S. Wilmer and A. Zukauskaite, 57-73. New York: Routledge.

Lupton, D. 2012. Medicine as culture. Illness, disease and the body. London: Sage.

Mackenzie, C., and N. Stoljar. 2000. Relational autonomy. Feminist perspectives on autonomy, agency, and the social self. Oxford: Oxford University Press.

Martin, S., S. Kelly, A. Khan, S. Cullum, T. Dening, G. Rait, C. Fox, C. Katona, T. Cosco, C. Brayne, and L. Lafortune. 2015. Attitudes and preferences towards screening for dementia: A systematic review of the literature. BMC Geriatrics. https://doi.org/10.1186/s12877-015-0064-6.

Marzuillo, C. 2014. Predictive genetic testing for complex diseases: A public health perspective. QJM: An International Journal of Medicine 107 (2): 93-97.

Metschke, R., and R. Wellbrock. 2002. Datenschutz in Wissenschaft und Forschung. Materialien zum Datenschutz.

Milne, R., E. Bunnik, A. Diaz, E. Richard, S. Badger, D. Gove, J. Georges, K. Fauria, J.-L. Molinuevo, K. Wells, C. Ritchie, and C. Brayne. 2018. Perspectives on communicating biomarker-based assessments of Alzheimer's disease to cognitively healthy individuals. Journal of Alzheimer's Disease 62 (2): 487-498.

Parsons, E.P., and P. Atkinson. 1992. Lay constructions of genetic risk. Sociology of Health \& Illness 14 (4): 437-455.

Perry, J., S. Wöhlke, A. Heßling, and S. Schicktanz. 2016. Why take part in personalized oncology research? Genetic misconception and genetic responsibility as critical issues from an ethical perspective. Journal of Oncology 26: e12563.

Rauscher, M.A., M. Dean, and G.M. Campbell-Salome. 2018. "I am uncertain about what my uncertainty even is": Men's uncertainty and information management of their BRCA-related cancer risks. Journal of Genetic Counseling. https://doi.org/10.1007/s10897-018-0276-y.

Raz, A.E., and S. Schicktanz. 2009. Diversity and uniformity in genetic responsibility: Moral attitudes of patients, relatives and laypeople in Germany and Israel. Medicine, Health Care and Philosophy 12 (4): 433-442. 
Rose, N. 2007. Genomic susceptibility as an emergent form of life? Genetic testing, identity, and the remit of medicine. In Biomedicine as culture. Instrumental practices, technoscientific knowledge, and new modes of life, ed. R.V. Burri and J. Dumit. New York: Routledge.

Ross, L.F., H.M. Saal, K.L. David, and R.R. Anderson. 2013. Technical report: Ethical and policy issues in genetic testing and screening of children. Genetics in Medicine 15 (3): 234-245.

Schaper, M., S. Wöhlke, and S. Schicktanz. 2018. "I would rather have it done by a doctor":laypeople's perceptions of direct-to-consumer genetic testing (DTC GT) and its ethical implications. Medicine, Health Care and Philosophy. https://doi.org/10.1007/s11019-018-9837-y.

Schicktanz, S. 2018. Genetic risk and responsibility: Reflections on a complex relationship. Journal of Risk Research 21 (2): 236-258.

Schneider, N., and C. Langner. 2014. Prognostic stratification of colorectal cancer patients: Current perspectives. Cancer Management and Research 6: 291-300.

Schwartz, L.M., and S. Woloshin. 2011. Communicating uncertainties about prescription drugs to the public: A national randomized trial. Archives of Internal Medicine 171 (16): 463-468.

Sorenson, J.R., T. Jennings-Grant, and J. Newman. 2004. Communication about carrier testing within hemophilia A families. American Journal of Medical Genetics Part C: Seminars in Medical Genetics 119C (1): 3-10.

Timman, R., R. Roos, A. Maat-Kievit, and A. Tibben. 2004. Adverse effects of predictive testing for Huntington disease underestimated: Long-term effects 7-10 years after the test. Health Psychology 23 (2): 189-197.

Watson, E.K., D. Shickle, N. Qureshi, J. Emery, and J. Austoker. 1999. The 'new genetics' and primary care: GPs' views on their role and their educational needs. Family Practice 16 (4): 420-425.

Weaver, M. 2016. The double helix: Applying an ethic of care to the duty to warn genetic relatives of genetic information. Bioethics 30 (3): 181-187.

Whyte, S., A. Green, M. McAllister, and H. Shipman. 2016. Family communication in inherited cardiovascular conditions in Ireland. Journal of Genetic Counseling 25 (6): 1317-1326.

Wöhlke, S., Schaper, M., Oliveri, S., Cutica, I., Spinella, F., Steinberger, D., Pravettoni, G., Schicktanz, S. under review. German and Italian users of web-accessed genetic data: Attitudes on personal utility and personal sharing preferences. Results of a comparative survey $(n=192)$.

Wöhlke, S., M. Schaper, and S. Schicktanz. 2019. How do moral uncertainty influence lay people's attitudes and risk perceptions concerning predictive genetic testing and risk communication. Frontiers in Genetics. https://doi.org/10.3389/fgene.2019.00380.

Wouters, R.H.P., R.M. Bijlsma, M.G. Ausems, J.J. van Delden, E.E. Voest, and A.L. Bredenoord. 2016. Am I my family's keeper? Disclosure dilemmas in next-generation sequencing. Human Mutation 37 (12): 1257-1262.

Publisher's Note Springer Nature remains neutral with regard to jurisdictional claims in published maps and institutional affiliations.

Sabine Wöhlke is a Research Associate at the Department of Medical Ethics and History of Medicine at the University Medical Center Göttingen. Her main interests are ethical and social aspects of personalized medicine, e.g., predictive genetic testing and biomarker research. She works with an empirical ethics approach and has experience with socio-empirical research in the field of patient-physician communication and shared decision-making.

Julia Perry is a Research Associate at the Department of Medical Ethics and History of Medicine at the University Medical Center Göttingen. Her research interests include social and ethical implications of predictive genetic testing, research participation, and research ethics. She is currently working on her $\mathrm{Ph}$.D. on sociological aspects of dementia prediction and participation in dementia research. 